\title{
Trans-catheter Treatment of Lutembacher Syndrome -A Case Report
}

\author{
ABM Abdus Salam, SK. Ziarat Islam², Kazi Abul Hasan³, Saiful Islam Azad ${ }^{4}$, Ataul Haque ${ }^{1}$, \\ Abdullah Shariar ${ }^{1}$, Naznin Umme Zakia ${ }^{1}$, Shahina Akter Mita ${ }^{1}$ \\ ${ }^{1}$ Department of Pediatric Cardiology, National Institute of Cardiovascular Disease, Dhaka, \\ ${ }^{2}$ Department of Cardiology, National Institute of Cardiovascular Disease, Dhaka, ${ }^{3}$ Department of \\ Pediatric Cardiac Surgery, National Institute of Cardiovascular Disease, Dhaka, ${ }^{4}$ Department of \\ Anaesthesia, National Institute of Cardiovascular Disease, Dhaka
}

\begin{abstract}
Key Words :
Trans-catheter

closure,

Lutembacher

syndrome, Atrial

Lutembacher syndrome is a rare combination of congenital Atrial Septal Defect (ASD) and acquired Rheumatic Mitral Stenosis (MS).It is usually treated by surgical repair with potential risk of cardiopulmonary bypass. With the advancement of interventional methods of treatment it is amenable to nonsurgical transcatheter management. We are reporting a case of Lutembacher syndrome that was successfully treated with percutaneouos Inoue balloon mitral valvuloplasty and device closure of atrial septal defect.
\end{abstract}

Abstract:

septal defect,

Mitral stenosis.

(Cardiovasc. j. 2015; 7(2): 162-165)

\section{Introduction:}

Lutembacher syndrome was first described by a French cardiologist, Rene Lutembacher in $1916 .^{1}$ It is the combination of congenital Atrial septal Defect (ASD) \& acquired Mitral stenosis ((MS).There is specific type of hemodynamic in this combination of two defects. Mitral stenosis augments the left to right to shunt through the ASD, but decompression of the obstructed left atrium due to MS attenuates its symptoms. ${ }^{2,3}$ The combination of these two conditions has hemodynamic influence on each other and the degree of MS may be under estimated. ${ }^{4}$ The condition is usually treated surgically, however, both abnormalities are amenable to percutaneous therapy. ${ }^{5}$

Combined transcatheter therapy was first described by Ruiz et al in $1992 .{ }^{6}$ Here we report a case of a patient with Lutembacher syndrome who was benefited from combined transcatheter therapy of balloon Valvuloplasty for MS and device closure for ASD.

\section{Case Summary:}

Mrs. X, age-25 years, presented with the complaints of exertional dyspnea for 5 years. She had repeated history of sore throat followed by insidious onset of arthritis with fever at the age
10 years which was diagnosed as Rheumatic fever. She was treated with medication and was on prophylactic penicillin for last 15 years. On physical examination, Pulse-86/minute, Respiratory rate20/minute, Blood pressure-125/75 mm of Hg. Chest $\mathrm{X}$-ray showed borderline cardiomegaly, ECG showed right bundle branch block (RBBB) with Right axis deviation. Echocardiography revealed congenital ASD Secundum with acquired MS due to chronic rheumatic fever. ASD size was $10 \times 12 \times 14$ $\mathrm{mm}$ with left to right shunt, mild pulmonary hypertension (PAH) with systolic pressure (PASP) $42 \mathrm{~mm}$ of $\mathrm{Hg}$. Mitral valve area (MVA) $-1.25 \mathrm{~cm}^{2}$, Peak pressure gradient (PPG)-20 mmHg, Mean pressure gradient (MPG)-14 mmHg. Anterior mitral leaflet (AML) \& posterior mitral leaflet (PML) were thickened but pliable with diastolic doming of AML, mild subvalvular change, no calcification. Left atrium (LA) was dilated. No spontaneous echo contrast or any thrombus was seen. She underwent Transesophageal Echo (TEE) study for the determination of size of the Atrial Septal Occluder (ASO).

\section{Procedure:}

Although, surgical treatment is gold standard treatment involving mitral valve replacement

Address of Correspondence: Dr ABM Abdus Salam, Department of Pediatric Cardiology, National Institute of Cardiovascular Disease, Dhaka, Bangladesh. Email: drsalam_12@yahoo.com 
(MVR) and pericardial patch closure of ASD secundum with cardiopulmonary bypass (CPB), the patient preferred non-surgical interventional method of treatment. So she was treated with Percutaneous Trans- luminal Mitral valve Commusurotomy (PTMC) followed by Transcatheter closure of ASD.

Under local anesthesia, right femoral vein was punctured and a $6 \mathrm{~F}$ sheath was introduced. Firstly, PTMC was done. Then ASD was closed with an Amplatzer device under transthoracic echocardiographic guidance.The patient was given Antibiotic for 5 days \& Aspirin $75 \mathrm{mg}$ daily for six months. She was discharged on $3^{\text {rd }}$ day with followup advice at 1, 3, $6 \& 12$ months.

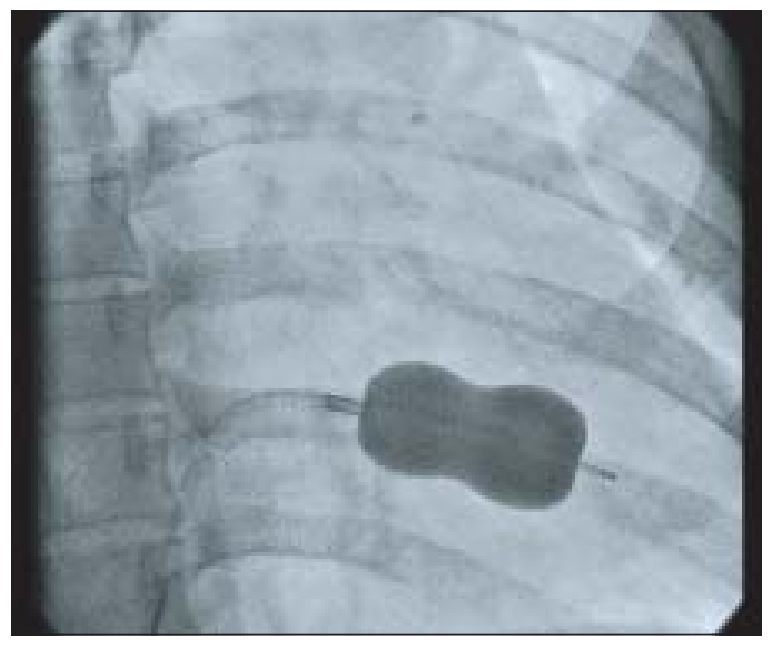

Fig.-1: PTMC by using Inoue balloon.

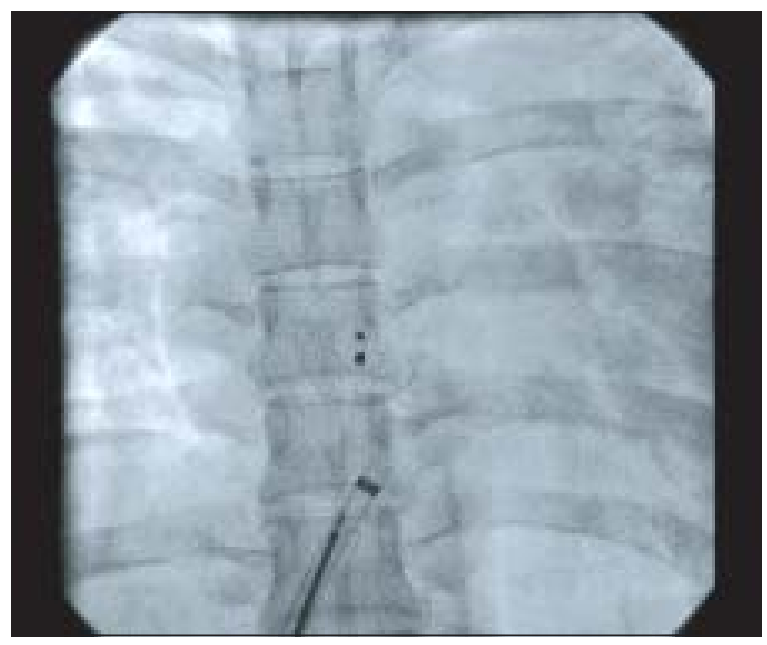

Fig.-2: $A S D$ closure using Amplatzer device

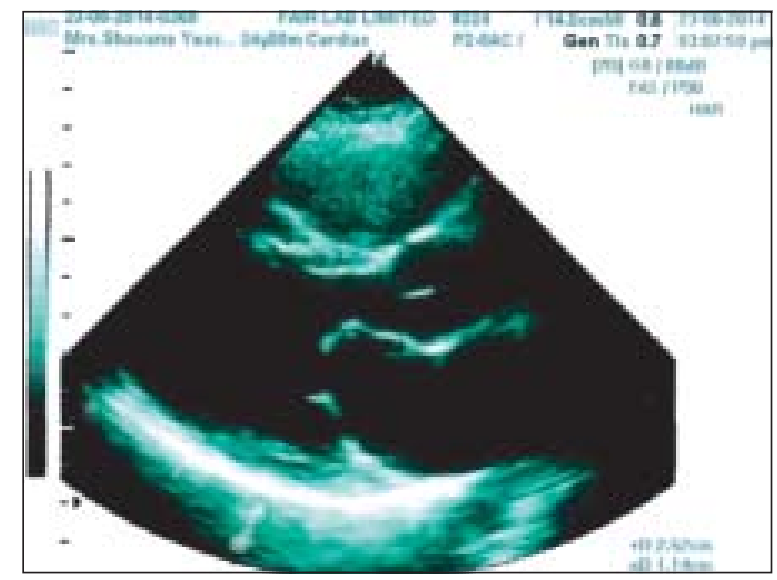

Fig.-3: $M V$ opening after intervention

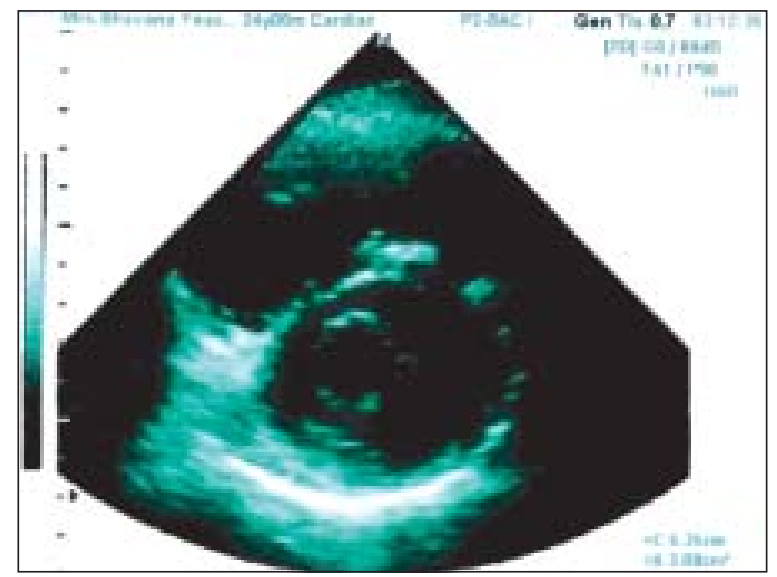

Fig.-4: $M V A-3.08 \mathrm{~cm}^{2}$ after intervention

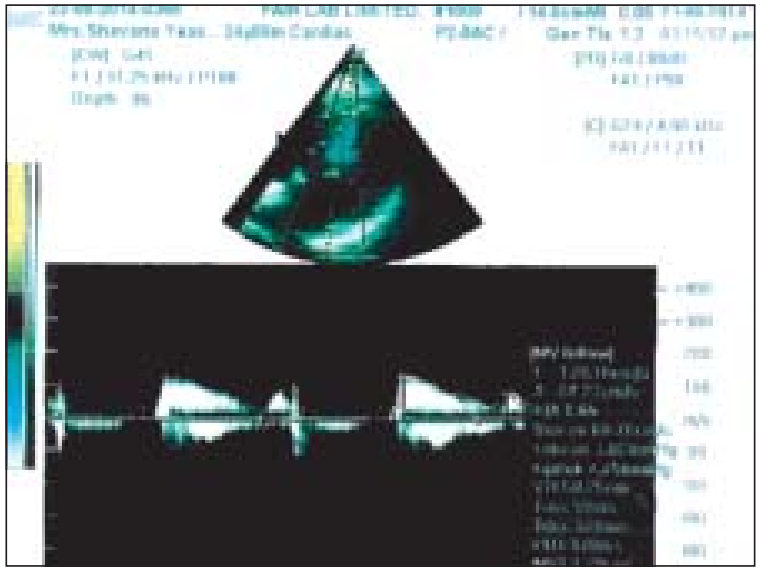

Fig.-5: Trans-valvular gradient 


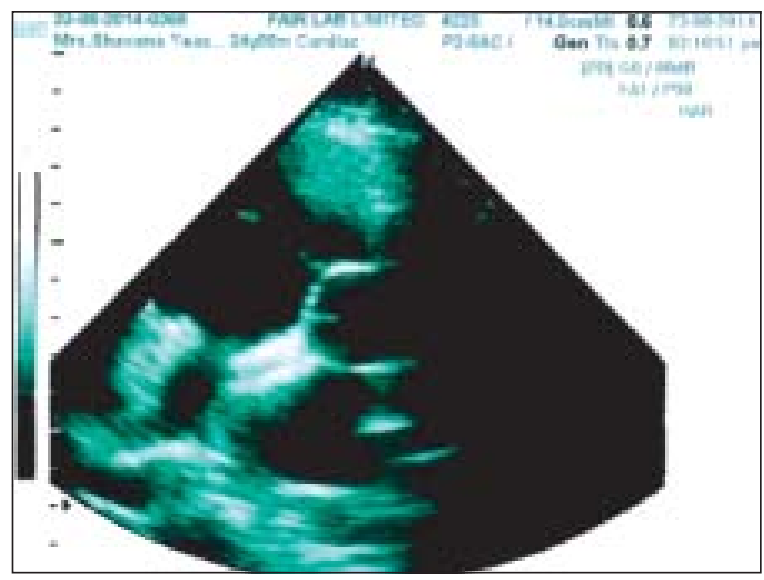

Fig.-6: $A S D$ device in situ

After the procedure, the patient attended two follow-up visits \& found quite free of symptoms. Echo follow-up showed no residual shunt across ASD device \& transmitral gradient was PPG -7 $\mathrm{mmHg} \&$ MPG- 5mmHg, indicating absolutely near normal.

\section{Discussion:}

The original case of Lutembacher syndrome was a female of 61 years old who had been pregnant for 7 times. Female preponderance is seen in both ASD \& MS, and thus Lutembacher syndrome has a predilection for female. ${ }^{1,2}$ The incidence of MS in ASD is 4\% and conversely the incidence of ASD in patients with MS is $0.6-0.7 \%{ }^{7}$ The hemodynamic effects of these coexisting ASD \& MS is different from that of isolated ASD or MS. MS augments left to right shunting through ASD, while the nonrestrictive ASD decompreses the left atrum reducing the diastolic mitral gradient. ${ }^{8}$ The pressure half time method consistently overestimates the mitral valve area. The extent of overestimation is greater in patient with larger ASD. The hemodynamic pressure half time is independent of the mitral valve area, chamber compliance and peak trans-mitral gradient. The hemodynamic pressure half time with Doppler method is dependent on the magnitude of the atrial shunt, although the correlation obtained is fair $(\mathrm{r}=0.61)$, indicating that the Doppler method is an inaccurate measure of the mitral valve area wherever an atrial shunt coexist with MS. Planimetry and the Doppler continuity equation methods yield an accurate mitral valve area in the Lutembacher Syndrome. ${ }^{2,9}$ There is late development of patient's symptoms particularly development of pulmonary hypertension in Lutembacher syndrome. ${ }^{10}$ It results from decompression of left atrial high pressure due to MS by means of left to right shunting through ASD. The magnitude of this shunt depends upon the compliance of the left \& right ventricles. The blood flows into the right atrium due to left sided obstruction by MS instead of passing into the pulmonary veins thus avoiding pulmonary congestion. This happens at the cost of progressive dilatation and ultimately, failure of the right ventricle and reduced blood flow to the left ventricle. Development of Eisenmenger syndrome or irreversible pulmonary vascular disease is very uncommon in the presence of large ASD and high left atrial pressure due to MS. ${ }^{11}$ This ameliorating role of ASD in MS was evident in original Lutembacher's report of 1916; the patient was a 61 year old woman who had been pregnant seven times. ${ }^{1,12}$ An earlier case report in the literature by Perllof in 1880 was a 74 year woman who had endured 11 pregnancies. ${ }^{7}$ Survival to advanced age has also been reported in another instance; an 81 years old woman experienced no symptoms related to her heart disease until she reached 75 years of age. ${ }^{13}$ These favorable reports, however, should not obscure the fact that the long-term natural history of ASD is unfavorably influenced by MS, which augments the left to right shunt and predisposes to atrial fibrillation and right ventricular failure. ${ }^{14}$ So, if patient is diagnosed at late stage, pulmonary hypertension and heart failure develops and the prognosis is bad. ${ }^{15}$

Previously, surgical treatment with cardiopulmonary by pass (CPB) was the gold standard method of treating Lutembacher syndrome. But with the advent of transcatherter ASD device closure particularly the Amplatzer Septal Occuluder \& PTMC with Inoue balloon technique, now a days, surgery is replaced by this non-surgical method with lot of advantages. These include, avoidance of complications associated with open heart surgery particularly during cardiopulmonary bypass, general anesthesia, hazards of blood transfusion, quicker recovery with a short hospital stay. ${ }^{2}$ But the only disadvantage is that in case of restenosis of mitral valve, repeat trans-septal puncture would not be possible but that can even be possible by trans-arterial retrograde non-trans-septal technique in which 
entry into the left atrium is achieved via the left ventricle, or one can go for surgery either CMC or MVR whatever indicated. ${ }^{16}$ There are few experiences with Transcatheter treatment of Lutembacher syndrome..$^{2-6,17}$ The use of percutaneous treatment of the Lutembacher syndrome was first described by Ruiz et al in 1992 . Combined umbrella closure of ASD with Lock's Clamsher occluder in conjunction with mitral and aortic balloon valvotomies was carried out with single balloon valvotomy \& double balloon for mitral valvotomy as a palliative rescue procedure in 43 year-old female and severe pulmonary hypertension to improve the risk prior to surgical repair. After wards, she refused surgery and died suddenly a few weeks later. With the advent of Amplatzer Septal Occluder (ASO), the first successful Transcatheter therapy of Lutembacher's syndrome was described by Joseph et al. ${ }^{17}$

Currently, the Inoue balloon is most widely used for mitral vavuloplasty and Amplatzer Septal Occluder (ASO) is used for percutaneous ASD closure. The successful combined use of these two devices was described by Chau et al. ${ }^{18} \mathrm{We}$ performed device closure of ASD under TTE guidance \& local anaesthesia. The advantages of percutaneous correction over surgical correction includes the avoidance of complications of open heart surgery, quick recovery and short hospital stay, but if patient develops mitral valve restenosis, either surgery or retrograde percutaneous therapy would be required.

\section{Conclusion:}

Non-surgical Transcatheter treatment of Lutembacher Syndrome is a safe procedure if the lesions are suitable for intervention avoiding invasive open heart surgery.

\section{Conflict of Interest - None.}

\section{References:}

1. Lutembacher R. De la stenose mitral avec communication interauriculaire. Arch Mal Coeur Vaiss 1916; 9:237-260.

2. Behjiatiardakani M,Rafiei M, Nough $H$ et al,Transcatheter Therapy of Lutembacher syndrome: a case report. Acta Medica Iranica 2011; 49 (5): 327-330.s

3. Aroney C, Lapnum W, Scalia G, Parsonage W. Transcatheter treatment of Lutembacher syndrome. Intern Med $J$ 2003;33(5-6):259-260.
4. Ho CL, Liang KW, Fu YC, Jan SL, et al, Transcatheter therapy of Lutembacher syndrome. J Chin Med Assoc 2007 Jun; 70 (6):253-256.

5. Ahmed WH, Al Shaibi KF, Chamsi-Pasha H, Abdemenem A. Nonsurgical correction of Lutembacher syndrome. Saudi Med J 2003;24(3):307-308.

6. Ruiz CE,Gamra H, Mahrer P, Allen JW, O' Laughlin MP, Lau FY. Percutaneous closure of a secundum atrial defect and double balloon valvotomoies of severe mitral and aortic valve stenosis in a patient with Lutembacher's syndrome and severe pulmonary hypertension. Catheter Cardiovasc Diag 1992;25(4):309-12.

7. Perloff JK. Atrial septal Defect.In: The clinical recognition of congenital heart disease: Saunder; 1994; 233-299.

8. Pan JP, Chen CY, Hsu TL, Wang SP, Chiang BN, Chang MS. Response of left ventricular ejection performance following balloon valvuloplasty in patient with mitral stenosis. Zhonghu Yi Xue Za Zhi (Taipei) 1992;49(5): 303-312.

9. Ruiz CE, Gamra H, Maher P, Allen JW, O'Laughin MP, Lau FY. Percutaneous closure of a secundum atrial septal defect and double balloon valvotomies of severe mitral and aortic valve stenosis in patient with Lutembacher's syndrome and pulmonary hypertension. Catheter Cardiovasc Diag 1992;25(4);309-312.

10. Sabbir M, Ahmed W, Akhter K.Transcatheter treatment of Lutembacher's syndrome. J Coll Physicians Surg Pak 2008, Vol 18 (2) 105-106.

11. Vasan RS, Shrivastava S, Kumar MV. Value and limitations of Doppler echocardiographic determination of mitral valve area in Lutembacher syndrome. $\mathrm{J} \mathrm{Am}$ Coll Cardiol 1992;20(6): 1362-1370.

12. Sandhya S.Kulkarni, Amit K.Sakaria, Sanket K.Mahajan et al. Lutembacher's Syndrome : $J$ Cardiovasc Dis Res 2012, April; 3(2): 179-181.

13. Rosenthal L. Atrial Septal Defect with Mitral Stenosis (Lutembacher Syndrome) in a woman of 81. BMJ 1956; 2: 1351 .

14. Cheng TO. Coexistent atrial septal defect and mitral stenosis (Lutembacher syndrome): An ideal combination for percutaneous treatment. Catheter Cardiovasc Interv 1999; 48 : 205-206. [PubMed].

15. Levin AR, Spach MS, Boimeau JP et al. Atrial Pressure flow dynamics and atrial septal defects (Secundum type), Circulation 1968 ; 37 : 476-488.

16. Cheng TO. Coexistent atrial septal defect and mitral stenosis (Lutembacher syndrome): An ideal combination for percutaneous treatment. Catheter Cardiovasc Interv 1999; 48 (2) :205-206.

17. Joseph G, Abhaichand Rajpal K, Kumar KP. Catheter Cardiovasc Interv 2005; 1999; 48(2):199-204.

18. Chau EM, Lee CH, Chow WH. Transcatheter treatment of a case of Lutembacher's syndrome. Catheter Cardiovasc Interv 2000; 50: 68-70. 